\title{
The effects of visual similarity on proofreading for misspellings
}

\author{
ALICE F. HEALY \\ Yale University, New Haven, Connecticut 06520, and \\ Haskins Laboratories, New Haven, Connecticut 06510
}

\begin{abstract}
In three experiments, subjects read prose passages and circled misspellings in them. The misspelled words were created by replacing a single letter with another one. The visual similarity between the correct letter and the one that was substituted for it increased the percentage of proofreading errors. The results suggest that proofreaders search through a visual representation of the text and that a hierarchical feature test is applied to this representation, according to which subjects give first priority to resolving letter envelope and second priority to discriminating additional visual features. A sophisticated-guessing decision rule is also implicated for the misspellings that do not alter letter envelope: Subjects are tolerant of missing letter features but are intolerant of additional features.
\end{abstract}

When individuals proofread for misspellings, do they search a phonetic representation of the text or a visual one? Several studies have provided evidence for the role of phonetic recoding in proofreading tasks. For example, Corcoran (1967) conducted a proofreading experiment in which letters were omitted from various words in a prose passage and subjects were asked to indicate the locations at which letters were missing. As in his earlier study of letter cancellation (Corcoran, 1966), Corcoran found that subjects made more errors on silent es than on pronounced es in the proofreading task. Similarly, Corcoran and Weening (1968) found that subjects made more errors in a proofreading task on silent ks than on pronounced ks. In another proofreading study by MacKay (1968), subjects were asked to read sentences containing misspelled words and to indicate the words in which they perceived a misspelling. Two types of misspellings were introduced: phonetically compatible ones, which would be pronounced in the same way as the original word (e.g., "work" misspelled as "werk"), and phonetically incompatible ones (e.g., "work" misspelled as "wark"). Phonetically incompatible misspellings were noticed more frequently than compatible ones. (See Cohen, 1980, for a related finding.)

This research was supported in part by a grant from the Spencer Foundation to Yale University, NSF Grants BNS $77-00077$ and BNS 80-00263 to Yale University and BNS 80-25020 to the University of Colorado, NICHD Grant HD01994 to Haskins Laboratories, and BRS Grant RR05596 to Haskins Laboratories. The author was supported by a Senior Faculty Fellowship from Yale University during the preparation of this manuscript. The author is indebted to Janice Chung and Rick Arons for help with the design, conduct, and analyses of the experiments, to Adam Drewnowski, William Estes, Peter Podgorny, and Bruno Repp for helpful discussions about this research, and to Mary LaRue for a careful reading of an earlier version of this manuscript. Requests for reprints should be sent to Alice F. Healy, who is now at Department of Psychology, University of Colorado, Muenzinger Building, Campus Box 345, Boulder, Colorado 80309.
On the other hand, several more recent studies have demonstrated the importance of visual factors in proofreading. Holbrook (1978) found effects of the visual similarity between the correctly spelled and misspelled words in a proofreading task. Likewise, Haber and Schindler (1981) have reported that misspellings are easier to detect when the correctly spelled and misspelled words differ in shape than when they are similar in shape.

One goal of the present study was to determine the nature of the text representation that is searched by proofreaders. The second aim was to investigate the search process in more detail, in order to determine the nature of the information processing strategies, or rules, employed by proofreaders.

\section{EXPERIMENT 1}

In the first experiment, the type of the to-be-detected misspelling was systematically manipulated. Misspelled words were created by substituting a single letter in a word with another one. (A similar "substitutionproofreading" task was used by Healy, 1980.) Four types of substitutions were made: Either vowels were replaced by other vowels and consonants by other consonants or vowels were replaced by consonants and consonants by vowels. If misspelled words are not detected when they are phonetically similar to the original words, then substitutions within letter type (e.g., "less" misspelled as "lesc") should yield more errors than substitutions between letter types (e.g., "less" misspelled as "leso"), which tend to alter the syllabic structure of the word as well as the sound of the substituted letter. In order to equate roughly the effects of visual similarity for substitutions within letter type and between letter types, only four different letters were employed in the substitutions: s, c, e, and $o$, all of which are short letters (not ascenders or 
descenders) and thus are roughly similar in shape (cf. Bouma, 1971).

\section{Method}

Subjects. One hundred and sixteen male and female Yale undergraduates participated as volunteer subjects.

Design and Materials. Two versions of a 387 -word prose passage were constructed. The passage was based on a selection from a chapter by Miller (1973). Forty misspellings were introduced into each version of the passage, with the following four constraints.

(1) No misspellings occurred within the first 10 and final 17 words of the passage. The remaining 360 words were divided into 40 blocks of 9 successive words. One misspelling was placed in each of the 40 blocks, with the location of the misspelling within the nine words in a block determined in a pseudorandom fashion, so that the subject could not anticipate when a misspelling would occur on the basis of its location in the passage.

(2) All the misspellings were created by substituting one of the letters within the correctly spelled word with another letter. None of the substitutions yielded a correctly spelled word.

(3) The letter substitutions involved only four different letters-two vowels, e and $o$, and two consonants, $s$ and $c-$ and were further restricted so that each letter was replaced by only two of the remaining letters, one of which was a vowel and one of which was a consonant. Specifically, the substitutions were restricted to the following eight types: $c$ for $s, s$ for $c, e$ for $o, o$ for $e, o$ for $s, s$ for $o$, e for $c$, and $c$ for e. Each of these eight types of substitutions occurred equally often, and every set of eight successive misspellings included one of each type, with the order of types pseudorandom. See Table 1 for examples of the eight types of misspellings. (Note that if a misspelling of one of the types used here were removed from the context of the prose passage, it would not always be possible to determine with certainty what the correctly spelled word was. For example, out of context, the misspelling "exict" could have been derived from either "exist" or "exact." However, since the misspellings in the experiment did not occur out of context but, rather, occurred in the context of a prose passage, such ambiguity is not a problem.)

(4) The two versions of the passage were identical except for the specific substitutions employed. If a given letter was replaced by a consonant in one passage, it was replaced by a vowel in the other passage. For example, if an $s$ was replaced by a $c$ in one passage, it was replaced by an o in the other passage. Thus, the word "less" was misspelled "lesc" in one passage and "leso" in the other passage.

Each version of the passage was typed with single spacing on a single page by means of a Diablo 1620 typewriter terminal with an Elite 12 print wheel and a black multistrike (film) ribbon. The passage was photocopied for distribution to the subjects. Instruction sheets were prepared with the same apparatus.

Each subject was given a copy of one of the two versions,

Table 1

Examples of Misspellings Used in Experiment 1

\begin{tabular}{cl}
\hline Substitution Type & Examples \\
\hline$s$ to $c$ & exict \\
$\mathrm{c}$ to $\mathrm{s}$ & sountry \\
o to e & anether \\
e to o & roady \\
$\mathrm{s}$ to o & leso \\
o to $\mathrm{s}$ & absut \\
$\mathrm{c}$ to e & teehnology \\
e to $\mathrm{c}$ & students \\
\hline
\end{tabular}

Table 2

Means and Standard Errors for Percentages of Proofreading Errors as a Function of Substitution Type in Experiment 1

\begin{tabular}{crr}
\hline Substitution Type & Mean & SE \\
\hline s to c & 1.4 & .5 \\
c to s & 8.3 & 1.3 \\
o to e & 11.2 & 1.5 \\
e to o & 8.6 & 1.3 \\
s to o & .7 & .3 \\
o to s & 4.5 & .9 \\
c to e & 10.5 & 1.4 \\
e to c & 59.5 & 3.6 \\
\hline
\end{tabular}

preceded by a copy of the instruction sheet. Each version was shown to half the subjects.

Procedure. The subjects were tested in a group session conducted in a classtoom. They were instructed to read the prose passage at their "normal reading speed," but whenever they came to a spelling error they were to encircle it with their pen or pencil. The subjects were told that if at any time they realized that they had missed an error in a previous word, they should not retrace their steps to encircle it and that they should not slow down their reading speed in order to be over-cautious about catching the errors.

\section{Results}

The results are summarized in Table 2, which includes the means and the standard errors of the means for the percentages of proofreading errors made by the subjects as a function of the letters involved in the substitution. Only errors in which the subject failed to circle a misspelled word (misses) are considered here and in the subsequent experiments in this study, since very few errors occurred in which subjects circled correctly spelled words (false alarms). One enormous, but unexpected, effect is evident: The percentage of errors in which the letter e was replaced by the letter c (e.g., "messagc") is much larger than the percentage of errors made on the other letter pairs.

A multifactorial repeated-measures analysis of variance was conducted on these data, including the following three factors: (1) substitutions involving phonetically similar words (both consonants or both vowels in the pair) vs. substitutions involving phonetically dissimilar words (one consonant and one vowel in the pair), ${ }^{1}$ (2) substitutions in which the correct letter was a consonant vs. substitutions in which the correct letter was a vowel, (3) substitutions in which the correct letter was either $\mathbf{s}$ or o vs. substitutions in which the correct letter was either $c$ or e. Because of the enormous difference between the substitutions in which e was replaced by $c$ and the other types of substitutions, each of these three factors was highly significant, as were all the interactions among them $(\mathrm{p}<.001$ in each case). For 84 of the 116 subjects, more errors were made on substitutions in which e was replaced by $c$ than on any of the other seven types of substitutions.

Although acoustic similarity cannot account for this pattern of results, visual similarity may be involved. All four letters used for substitutions in this experiment are in the same shape category: They are all small letters, 
neither ascenders nor descenders. However, e and c are more visually similar than any other pair of letters, since they have the same envelope (cf. Bouma, 1971) and differ by only one feature. The asymmetrical pattern of errors, in which e-to-c substitutions were missed much more than c-to-e substitutions, is especially noteworthy and is reminiscent of a similar asymmetrical pattern discovered for the capital letters $\mathrm{C}$ and $\mathrm{G}$ in a tachistoscopic letter-recognition experiment described by Lindsay and Norman (1977, p. 267).

No evidence was provided in this experiment for the relevance of phonetic features of text to proofreading. In particular, letter substitutions that led to large differences in the sound of the word (as when a vowel was replaced by a consonant) were not detected more easily than those that led to smaller differences in the sound of the word (as when a vowel was replaced by another vowel). However, this failure to find effects of phonetic factors should not be taken to mean that phonetic factors are irrelevant to proofreading. The substantial number of studies reported in the literature that demonstrate the importance of phonetic factors to proofreading and visual search argue against this hypothesis. Further, it is possible that phonetic factors did play a role even in the present study but that they were overshadowed by the potent visual factors. This hypothesis is supported by the finding that substitutions involving the phonetically dissimilar letters $s$ and $o$ did indeed yield especially low error rates.

\section{EXPERIMENT 2}

The pattern of proofreading errors observed in Experiment 1 suggests that proofreaders search through a visual representation of the text. In addition, a specific information processing rule is suggested by the asymmetrical pattern of visual confusions: These results support a sophisticated-guessing decision rule in which subjects tolerate the absence of missing letter features but are intolerant of inappropriate features (see, e.g., Broadbent, 1967; Lindsay \& Norman, 1977; Rumelhart $\&$ Siple, 1974). Although asymmetries have been found in some of the previous studies of alphabetic confusions (e.g., Garner \& Haun, 1978; Gilmore, Hersh, Caramazza, \& Griffin, 1979; Lindsay \& Norman, 1977; Tversky, 1977), they have not been consistently found and have not always taken this form. An important difference between Experiment 1 of the present study and most of the earlier studies of alphabetic confusions is that single letters (e.g., Townsend, 1971), letter pairs (e.g., Podgorny \& Garner, 1979), or short words (e.g., Bouwhuis \& Bouma, 1979) were presented in the earlier studies, whereas letters were presented in a normal prose context in Experiment 1. To my knowledge, the only other proofreading experiment aimed at studying alphabetic confusions was the one by Holbrook (1978), who did report effects of visual similarity but did not discuss asymmetries.
Although visual factors can account for the results in Experiment 1, other factors may be important as well. The misspellings involving substitutions of $\mathrm{c}$ for $\mathrm{e}$ were derived from words different from those involving substitutions of e for c. Linguistic factors were thus confounded with visual factors in Experiment 1. Experiment 2 was therefore designed to control for such linguistic factors. Two methods were used for this purpose: (1) The text to be proofread was typed in two different formats, one with all capital letters and one with standard capitalization (so that no substituted letters were capitalized). Only visual factors, not linguistic ones, would be affected by changes in type case. For that reason, any differences found between the patterns of errors in the passages typed in the two formats can be attributed to visual factors. Response biases associated with different words or different letters were also controlled by this manipulation. (2) Three different linguistic factors were controlled across misspelled words involving a given pair of letters: the location of the substituted letter, the length of the word, and the frequency of the word. Specifically, these three variables were equated as closely as possible for misspellings involving substitutions in one direction (e.g., $c$ for e) and those involving substitutions in the opposite direction (e.g., e for c).

As in Experiment 1, misspelled words in Experiment 2 were created by replacing one letter in a word with another one. In order to provide a test of the asymmetrical decision rule proposed to account for the pattern of results in Experiment 1, four pairs of letters were chosen for study in Experiment 2. The letters in each one of these pairs differ in one of the type cases by only the presence of a single visual feature, by which is meant a small line segment. Two of the letter pairs differ by only the presence of a single feature when typed in lowercase, e/c and $h / n$, but not when typed in uppercase, $\mathrm{E} / \mathrm{C}$ and $\mathrm{H} / \mathrm{N}$. In contrast, two of the letter pairs differ by only the presence of a single feature when typed in uppercase, $R / P$ and $E / F$, but not when typed in lowercase, $r / p$ and $e / f$. If subjects do indeed use the asymmetrical decision rule, then more proofreading errors should occur on words in which a single letter feature is missing (as when e is replaced by $c, h$ is replaced by $n, R$ is replaced by $P$, or $E$ is replaced by $F$ ) than on words in which a single letter feature is added (as when $c$ is replaced by $e, n$ is replaced by $h, P$ is replaced by $R$, or $F$ is replaced by $E$ ).

\section{Method}

Subjects. Fifty male and female Yale undergraduates, who were students in a course in introductory psychology, participated as subjects for course credit.

Design and Materials. Two versions of a 1,225-word prose passage were constructed. The passage was an excerpt from an elementary textbook on social psychology by Aronson (1972). One hundred and twenty misspellings were introduced into each version of the passage, with the following five constraints.

(1) No misspellings occurred within the first 10 and final 15 words of the passage. The remaining 1,200 words were divided 
Table 3

Examples of Misspellings Used in Experiment 2

\begin{tabular}{cll}
$\begin{array}{c}\text { Substitution } \\
\text { Type }\end{array}$ & Lowercase & \multicolumn{1}{c}{ Uppercase } \\
\hline $\mathrm{c}$ to $\mathrm{e}$ & aecordingly & AECORDINGLY \\
$\mathrm{e}$ to $\mathrm{c}$ & potcnt & POTCNT \\
$\mathrm{n}$ to $\mathrm{h}$ & thah & THAH \\
$\mathrm{h}$ to $\mathrm{n}$ & brotner & BROTNER \\
$\mathrm{f}$ to $\mathrm{e}$ & oe & OE \\
$\mathrm{e}$ to $\mathrm{f}$ & cfrtain & CFRTAIN \\
$\mathrm{p}$ to $\mathrm{r}$ & rerson & RERSON \\
$\mathrm{r}$ to $\mathrm{p}$ & demonstpated & DEMONSTPATED \\
\hline
\end{tabular}

Table 4

Mean Values and Standard Errors of Word Frequency, Word Length, and Location of Substituted Letter for Each Substitution Type in Experiment 2

\begin{tabular}{|c|c|c|c|c|c|c|}
\hline \multirow{2}{*}{$\begin{array}{l}\text { Substitu- } \\
\text { tion Type }\end{array}$} & \multicolumn{2}{|c|}{ Frequency } & \multicolumn{2}{|c|}{ Length } & \multicolumn{2}{|c|}{ Location } \\
\hline & Mean & SE & Mean & SE & Mean & $\mathrm{SE}$ \\
\hline $\begin{array}{l}c \text { to } e \\
e \text { to } c\end{array}$ & $\begin{array}{l}423 \\
398\end{array}$ & $\begin{array}{l}238 \\
166\end{array}$ & $\begin{array}{l}7.3 \\
7.3\end{array}$ & $\begin{array}{l}.7 \\
.6\end{array}$ & $\begin{array}{l}.52 \\
.51\end{array}$ & $\begin{array}{l}.07 \\
.06\end{array}$ \\
\hline $\begin{array}{l}n \text { to } h \\
h \text { to } n\end{array}$ & $\begin{array}{l}3715 \\
5394\end{array}$ & $\begin{array}{l}2278 \\
4621\end{array}$ & $\begin{array}{l}6.0 \\
5.5\end{array}$ & $\begin{array}{l}.7 \\
.4\end{array}$ & $\begin{array}{l}.71 \\
.64\end{array}$ & $\begin{array}{l}.08 \\
.06\end{array}$ \\
\hline $\begin{array}{l}f \text { to } e \\
\text { e to } f\end{array}$ & $\begin{array}{l}5438 \\
1788\end{array}$ & $\begin{array}{r}3261 \\
748\end{array}$ & $\begin{array}{l}5.4 \\
5.3\end{array}$ & $\begin{array}{l}.7 \\
.6\end{array}$ & $\begin{array}{l}.53 \\
.63\end{array}$ & $\begin{array}{l}.09 \\
.08\end{array}$ \\
\hline $\begin{array}{l}p \text { to } r \\
r \text { to } p\end{array}$ & $\begin{array}{l}116 \\
110\end{array}$ & $\begin{array}{l}31 \\
25\end{array}$ & $\begin{array}{l}7.5 \\
8.1\end{array}$ & $\begin{array}{l}.6 \\
.6\end{array}$ & $\begin{array}{l}.30 \\
.37\end{array}$ & $\begin{array}{l}.06 \\
.07\end{array}$ \\
\hline
\end{tabular}

into 120 blocks of 10 successive words. One misspelling was placed in each of the 120 blocks, with the location of the misspelling within the 10 words in a block determined pseudorandomly.

(2) All the misspellings were created by substituting one of the letters within the correctly spelled word with another letter. None of the substitutions yielded a correctly spelled word.

(3) The letter substitutions involved four different letter pairs, two of which included letters that differ by only the presence of a single feature in lowercase but not in uppercase, $\mathrm{e} / \mathrm{c}$ and $\mathrm{h} / \mathrm{n}$, and two of which included letters that differ by only the presence of a single feature in uppercase but not in lowercase, $\mathrm{e} / \mathrm{f}$ and $\mathrm{r} / \mathrm{p}$. Eight types of substitutions were formed from these four pairs: $e$ for $c, c$ for $e, h$ for $n, n$ for $h$, $e$ for $f$, $f$ for $e, r$ for $p$, and $p$ for $r$. Each of these eight types of substitutions occurred 15 times in the passage, and every set of eight successive misspellings included one of each type, with the order of types pseudorandom. See Table 3 for examples of the eight types of misspellings employed in this experiment, printed in all lowercase letters and printed in all uppercase letters.

(4) The two types of substitutions involving the same letter pair (e.g., e for $c$ and $c$ for $e$ ) were equated as closely as possible in terms of three variables: (a) the frequency of the words that were misspelled, with the frequency determined by Kucera and Francis (1967), (b) the length of the misspelled words, and (c) the location of the substituted letter within the words, where, for example, the first letter in a sixtetter word has location $1 / 6=.17$ and the last letter has location $6 / 6=1.0$. Four sets of analyses of variance were conducted to compare the two types of substitutions involving the same letter pair, one set for each of the four letter pairs. Each set of analyses included three tests: one for frequency, one for length, and one for location. In no case was there a significant difference between the two types of substitutions including the same pair $(p>.285$ in each case). The mean values and the standard errors of the mean values of word frequency, word length, and location of the substituted letter are summarized in Table 4 for each substitu- tion type. The equating of the two types of substitutions involving a given letter pair on these variables was performed in order to insure that any asymmetrical pattern of errors could not be attributed to differences in these variables.

(5) The two versions of the passage were identical, except that one was typed in standard format ("standard"), with none of the substituted letters capitalized, and the other was typed with all capital letters ("capital").

Each version of the passage was typed with single spacing on two pages, by means of the same apparatus employed in Experiment 1. Photocopies of both versions of the passage and of the instruction sheet, which was prepared with the same apparatus as the passage, were distributed to the subjects. Half the subjects were given the standard version first, and half were given the capital version first.

Procedure. The subjects were tested in small groups ranging from one to seven subjects. The instructions given to the subjects were essentially the same as those used in Experiment 1, except that, in addition, the subjects were told that they would be reading two passages, that they were to go on to the second passage as soon as they finished the first passage, and that they should not refer to the first passage at any time when reading the second passage.

\section{Results}

The results are summarized in Table 5, which includes the means and the standard errors of the means for the percentages of proofreading errors made by the subjects as a function of the version of the passage and the letters involved in the-substitution. As in Experiment 1 , in the standard version of the passage, subjects made a great number of errors when e was replaced by $c$ but many fewer when $\mathrm{c}$ was replaced by e. This asymmetry seems to be attributable to visual factors, rather than linguistic ones, because both the number of errors and the size of the asymmetry were greatly reduced in the capital version of the passage. Although the other letter pairs also showed effects of capitalization, reflecting differences in visual similarity between the two letters in a pair in the two type cases, the asymmetry found for the pair $\mathrm{c}$ and $\mathrm{e}$ was not found for the other three pairs.

A multifactorial repeated-measures analysis of variance was conducted on these data and included the following three factors: (1) passage version (capital vs. standard), (2) letter pair, and (3) direction of substitution (correct letter had one fewer feature than substituted

Table 5

Means and Standard Errors for Percentages of Proofreading Errors as a Function of Substitution Type and Passage Version in Experiment 2

\begin{tabular}{cccccc}
\hline & \multicolumn{3}{c}{ Version } \\
\cline { 2 - 3 } $\begin{array}{c}\text { Substitution } \\
\text { Type }\end{array}$ & \multicolumn{2}{c}{ Standard } & & \multicolumn{2}{c}{ Capital } \\
\cline { 2 - 3 } \cline { 5 - 6 } & Mean & SE & & Mean & SE \\
\hline c to $\mathrm{e}$ & 8.7 & 1.5 & 7.2 & 1.3 \\
e to $\mathrm{c}$ & 41.5 & 4.7 & & 13.9 & 1.6 \\
n to $h$ & 20.1 & 2.2 & & 21.7 & 2.2 \\
h to $\mathrm{n}$ & 23.2 & 2.9 & & 23.3 & 2.4 \\
f to $\mathrm{e}$ & 6.7 & 1.3 & & 18.7 & 1.9 \\
e to $\mathrm{f}$ & 2.4 & 1.0 & 18.1 & 2.3 \\
p to $\mathrm{r}$ & 5.9 & 1.0 & 15.1 & 1.6 \\
r to $\mathrm{p}$ & 4.0 & 1.0 & 13.3 & 1.8 \\
\hline
\end{tabular}


letter or vice versa). All three factors were significant, as were all the interactions among them $(p<.05$ in each case). Separate analyses were also conducted on the data from each letter pair. For the pair c/e, as noted above, more errors were made on the standard version than on the capital version $[\mathrm{F}(1,49)=40.0, \mathrm{p}<.001]$; more errors were made when e was replaced by $c$ than when $c$ was replaced by e $[F(1,49)=53.7, p<.001]$, and this asymmetry was larger for the standard passage than for the capital passage $[F(1,49)=35.5, p<.001]$. In contrast, for the pair $\mathrm{f} / \mathrm{e}$, which is more visually similar in uppercase than in lowercase, more errors were made on the capital version than on the standard version $[F(1,49)=113.8, p<.001]$, and slightly more errors were made when $f$ was replaced by e than vice versa (an asymmetry opposite to that found for $e$ and $c$ in terms of visual features) $[F(1,49)=4.6, p=.035]$, but this asymmetry is probably not attributable to visual factors since it was not affected by passage version $[F(1,49)=1.9, p=.176]$. The letter pair $p / r$ showed a pattern of results similar to that found for $\mathrm{f} / \mathrm{e}$ : More errors were made on the capital version than on the standard version $[F(1,49)=58.0, p<.001]$, reflecting differences in visual similarity; a small (and in this case only marginally significant) asymmetry was found in the direction opposite to that for the c/e pair in terms of visual features $[\mathrm{F}(1,49)=3.6, \mathrm{p}=.061]$; and the size of the asymmetry was not affected by passage version $[\mathrm{F}(1,49)<1]$. The letter pair $\mathrm{n} / \mathrm{h}$, which is visually confusable in both lowercase and uppercase (uppercase $\mathrm{N}$ and $\mathrm{H}$ differ by only the slant of the middle line segment), demonstrated no effect of passage version $[F(1,49)<1]$, no effect of direction of substitution $[F(1,49)=2.2, p=.138]$, and no interaction between these two factors $[F(1,49)<1]$.

Although the results of this experiment lend further evidence for the importance of visual factors in proofreading because of the substantial effects of passage version, they do not provide unqualified support for the asymmetrical decision rule proposed above. The results for the letter pair $\mathrm{e} / \mathrm{c}$ are consistent with such a rule, but the results of the other letter pairs tested are not.

\section{EXPERIMENT 3}

Why does the letter pair e/c provide evidence for the asymmetrical decision rule, whereas the other letter pairs do not? One reasonable explanation is that missing features may be tolerated only when the original letter and the one replacing it have the same envelope, by which is meant "the smallest enclosing polygon without indentations" (Bouma, 1971, p. 463). The letters e and $c$ do have the same envelope, but $h$ and $n, E$ and $F$, and $\mathbf{P}$ and $\mathbf{R}$ do not. Hierarchical feature tests, in which subjects give first priority to resolving letter shape or envelope and second priority to processing other features, have also been proposed by Lupker (1979) and Massaro and Schmuller (1975).
In order to test this hypothesis, in all the misspellings employed in Experiment 3, wherever the correct letter and the letter substituted for it differed by a single feature, they had the same envelope. Therefore, the asymmetrical decision rule should apply in all cases in this experiment. Specifically, three pairs of letters were used for substitutions: one in which the letters differed by a single feature when typed in lowercase $(\mathrm{e} / \mathrm{c})$ but not in uppercase $(\mathrm{E} / \mathrm{C})$, one in which the letters differed by a single feature when typed in uppercase $(\mathrm{G} / \mathrm{C})$ but not in lowercase $(\mathrm{g} / \mathrm{c})$, and one with letters that differ by a single feature when typed in both lowercase $(\mathrm{o} / \mathrm{c})$ and uppercase $(\mathrm{O} / \mathrm{C})$. If the hierarchical feature test and asymmetrical decision rule apply, then more proofreading errors should be found on words in which a single feature is missing (when e is replaced by $c, G$ is replaced by $\mathrm{C}$, o is replaced by $\mathrm{c}$, or $\mathrm{O}$ is replaced by C) than on words in which a single feature is added (when $\mathrm{c}$ is replaced by $\mathrm{e}, \mathrm{C}$ is replaced by $\mathrm{G}, \mathrm{c}$ is replaced by $\mathrm{o}$, or $\mathrm{C}$ is replaced by $\mathrm{O}$ ).

\section{Method}

Subjects. Fifty-two young men and women who had responded to posters on the Yale University campus participated as subjects and were paid $\$ 2$. An additional five subjects were run, but their data were not included in the statistical analyses because four of them made an excessive number (4-29) of false alarm errors and one of them made an excessive number of misses (83).

Design and Materials. Four new versions of the 1,225-word prose passage used in Experiment 2 were constructed. (One word in the passage was altered-"responded" was changed to "reacted"-but the meaning was kept in tact.) Ninety misspellings were introduced into each version, with the following five constraints.

(1) As in Experiment 2, no misspellings occurred within the first 10 and final 15 words of the passage. The remaining 1,200 words were divided into 120 blocks of 10 successive words. One misspelling was placed in six of every eight successive blocks, with the locations of the six blocks and the locations of the misspelled words within the blocks determined pseudorandomly.

(2) All the misspellings were created by substituting one of the letters within the correctly spelled word with another letter. None of the substitutions yielded a correctly spelled word.

(3) The letter substitutions involved three different letter pairs, each of which included letters that had the same envelope when they were printed in the type case in which they were visually similar. One letter pair included letters that were visually similar (differed by only a single letter feature) in lowercase but not in uppercase $(\mathrm{e} / \mathrm{c})$, one letter pair included letters that were visually similar in uppercase but not in lowercase $(\mathrm{g} / \mathrm{c})$, and the remaining letter pair included letters that were visually similar in both uppercase and lowercase $(\mathrm{o} / \mathrm{c})$. Each of the six types of substitutions occurred 15 times in the passage, and every set of six successive misspellings included one of each type, with the order of types pseudorandom. See Table 6 for examples of the six types of misspellings employed in this experiment, printed in all lowercase letters and printed in all uppercase letters.

(4) As in Experiment 2, the two types of substitutions involving the same letter pair were equated as closely as possible in terms of three variables: (a) the frequency of the words that were misspelled, with frequency determined by Kučera and Francis (1967), (b) the length of the misspelled words, and (c) the locations of the substituted letters within the words. Three sets of analyses of variance were conducted to compare 
Table 6

Examples of Misspellings Used in Experiment 3

\begin{tabular}{cll}
$\begin{array}{c}\text { Substitution } \\
\text { Type }\end{array}$ & Lowercase & \multicolumn{1}{c}{ Uppercase } \\
\hline $\mathrm{c}$ to $\mathrm{e}$ & aecordingly & AECORDINGLY \\
$\mathrm{e}$ to $\mathrm{c}$ & potcnt & POTCNT \\
$\mathrm{c}$ to o & beoome & BEOOME \\
o to $\mathrm{c}$ & perscn & PERSCN \\
$\mathrm{c}$ to $\mathrm{g}$ & onge & ONGE \\
$\mathrm{g}$ to $\mathrm{c}$ & strancer & STRANCER \\
\hline
\end{tabular}

Table 7

Mean Values and Standard Errors of Word Frequency, Word Length, and Location of Substituted Letter for Each Substitution Type in Experiment 3

\begin{tabular}{|c|c|c|c|c|c|c|}
\hline \multirow{2}{*}{$\begin{array}{c}\text { Substitution } \\
\text { Type }\end{array}$} & \multicolumn{2}{|c|}{ Frequency } & \multicolumn{2}{|c|}{ Length } & \multicolumn{2}{|c|}{ Location } \\
\hline & Mean & SE & Mean & SE & Mean & SE \\
\hline $\mathrm{c}$ to $\mathrm{e}$ & 423 & 238 & 7.3 & .7 & .52 & .07 \\
\hline $\mathrm{e}$ to $\mathrm{c}$ & 670 & 418 & 7.2 & .7 & .50 & .07 \\
\hline$c$ to $o$ & 412 & 143 & 7.1 & .7 & .57 & .05 \\
\hline$o$ to $\mathrm{c}$ & 487 & 192 & 6.7 & .8 & .49 & .04 \\
\hline $\mathrm{c}$ to $\mathrm{g}$ & 104 & 35 & 7.7 & .5 & 56 & .07 \\
\hline $\mathrm{g}$ to $\mathrm{c}$ & 123 & 37 & 7.5 & .4 & .69 & .07 \\
\hline
\end{tabular}

the two types of substitutions involving the same letter pair, one set for each of the three pairs. The difference between the two types of substitutions within a pair was not significant in any of these analyses $(p \geqslant .214$ in each case). The mean values (and the standard errors of the mean values) of word frequency, word length, and location of the substituted letter are summarized in Table 7 for each substitution type.

(5) The four versions of the passage were identical, except that two were typed in standard format ("standard"), with none of the substituted letters capitalized, and two were typed with all capital letters ("capital"). The two versions with the same format differed in the print wheel employed. One version with a given format was constructed with the Elite 12 print wheel used in the previous experiments, and the other version was constructed with a Prestige Elite 12 print wheel. The characters on the two print wheels are similar but not identical, and the letter $\mathrm{c}$ seems somewhat less confusable with the letter $\mathrm{e}$ in the Prestige Elite 12 wheel than in the Elite 12 wheel.

All four versions of the passage were typed with single spacing on two pages, by means of the same apparatus employed in the previous experiments. Photocopies of each version of the passage and of the instruction sheet, which was prepared with the same apparatus, were made for distribution to the subjects. All subjects were shown one standard version of the passage and one capital version, with the order of versions counterbalanced across subjects. Half the subjects were given the two versions prepared with the Elite 12 wheel, and half were given the two versions prepared with the Prestige Elite 12 wheel.

Procedure. The procedure was the same as that used in Experiment 2.

\section{Results}

The results are summarized in Table 8 in terms of the means and the standard errors of the means for the percentages of proofreading errors made by the subjects as a function of the version of the passage and the letters involved in the substitution. No distinction is made between the versions typed with different print wheels, since a preliminary analysis revealed analogous patterns of results for the two print wheels. In this experiment, in which all visually similar letters had the same envelope, not only were the expected effects of capitalization obtained (more errors for $\mathrm{c} / \mathrm{e}$ in lowercase, more errors for $\mathrm{c} / \mathrm{g}$ in uppercase, and equal numbers of errors for $c / o$ in the two versions), but also the same asymmetrical pattern of errors was obtained for each of the three pairs of letters, and this pattern was more pronounced when visual similarity was greatest.

As in Experiment 2, a multifactorial repeatedmeasures analysis of variance was conducted on these data and included the following three factors: (1) passage version (capital vs. standard), (2) letter pair, and (3) direction of substitution. The main effects of letter pair $[F(2,102)=20.9, p<.001]$ and direction of substitution $[F(1,51)=72.4, p<.001]$ were significant, as were the interactions of passage version and letter pair $[F(2,102)=70.3, p<.001]$, letter pair and direction of substitution $[\mathrm{F}(2,102)=3.8, \mathrm{p}=.026]$, and the three-way interaction of these factors $[F(2,102)=21.4$, $\mathrm{p}<.001]$.

As in Experiment 2, separate analyses of variance were also conducted on the data from each letter pair. For the pair $\mathrm{c} / \mathrm{e}$, more errors were made in the standard passage than in the capital passage $[\mathrm{F}(1,51)=32.5$, $\mathrm{p}<.001]$, more errors were made when e was replaced by $c$ (so that a visual feature was missing) than when $c$ was replaced by e (so that a visual feature was added) $[F(1,51)=26.9, p<.001]$, and this asymmetry was greater for the standard passage than for the capital passage $[F(1,51)=18.9, p<.001]$. Conversely, for the pair $\mathrm{c} / \mathrm{g}$, more errors were made in the capital passage than in the standard passage $[F(1,51)=83.6, p<.001]$, in accordance with expectations based on visual similarity. As for the c/e pair, for the c/g pair, more errors were made when a visual feature was missing ( $\mathrm{g}$ was replaced by $c$ ) than when a feature was added ( $c$ was replaced by g) $[F(1,51)=63.5, p<.001]$, and this asymmetry was greater in the capital passage, in which the visual similarity was greater, than in the standard passage

Table 8

Means and Standard Errors for Percentages of Proofreading Errors as a Function of Substitution Type and Passage Version in Experiment 3

\begin{tabular}{|c|c|c|c|c|}
\hline \multirow{3}{*}{$\begin{array}{c}\text { Substitution } \\
\text { Type }\end{array}$} & \multicolumn{4}{|c|}{ Version } \\
\hline & \multicolumn{2}{|c|}{ Standard } & \multicolumn{2}{|c|}{ Capital } \\
\hline & Mean & SE & Mean & SE \\
\hline $\begin{array}{l}\mathrm{c} \text { to } \mathrm{e} \\
\mathrm{e} \text { to } \mathrm{c}\end{array}$ & $\begin{array}{r}9.4 \\
25.1\end{array}$ & $\begin{array}{l}1.5 \\
3.0\end{array}$ & $\begin{array}{r}7.8 \\
10.3\end{array}$ & $\begin{array}{l}1.4 \\
1.7\end{array}$ \\
\hline $\begin{array}{l}\mathrm{c} \text { to } \mathrm{o} \\
\mathrm{o} \text { to } \mathrm{c}\end{array}$ & $\begin{array}{r}7.7 \\
11.3\end{array}$ & $\begin{array}{l}1.2 \\
2.2\end{array}$ & $\begin{array}{r}4.6 \\
10.3\end{array}$ & $\begin{array}{r}.9 \\
1.6\end{array}$ \\
\hline $\begin{array}{l}\mathrm{c} \text { to } \mathrm{g} \\
\mathrm{g} \text { to } \mathrm{c}\end{array}$ & $\begin{array}{r}5.3 \\
10.5\end{array}$ & $\begin{array}{l}1.0 \\
1.1\end{array}$ & $\begin{array}{l}14.4 \\
27.7\end{array}$ & $\begin{array}{l}1.9 \\
2.3\end{array}$ \\
\hline
\end{tabular}


$[F(1,51)=20.2, p<.001]$. For the letter pair $c / o$, which is visually similar in both uppercase and lowercase, more errors were made when a visual feature was missing (o was replaced by $c$ ) than when a visual feature was added (c was replaced by o) $[\mathrm{F}(1,51)=12.3$, $p=.001]$, but there was no effect of passage version $[F(1,51)=3.0, p=.084]$ and no interaction between passage version and the direction of the substitution $[\mathrm{F}(1,51)<1]$.

For all three letter pairs used in this experiment, there was an asymmetrical pattern of errors favoring substitutions in which letter features were deleted rather than added. For the pairs $\mathrm{c} / \mathrm{e}$ and $\mathrm{c} / \mathrm{g}$, this asymmetrical pattern of errors was especially marked for the type case in which the correct letter and the one replacing it differed by only a single visual feature, but there was a small asymmetry for the other type case as well. The small asymmetry for uppercase $\mathrm{C} / \mathrm{E}$ and lowercase c/g may also be attributable to the deletion or addition of visual features, but the role of linguistic factors cannot be ruled out in these cases.

One linguistic factor that may be relevant to the observed asymmetry is the frequency in the language of the letters involved in the substitutions. According to single-letter frequency counts prepared by Mayzner and Tresselt (1965) and based on a sample of 20,000 English words, the letter e is considerably more frequent $(11,620)$ than the letter $c(2,057)$. This difference in frequency could account for why subjects mistake $c$ for e, but not vice versa. However, such a frequency difference cannot account for the similar asymmetric pattern observed with the letters $g$ and $c$, since $g$ is less frequent $(1,903)$ than $c \cdot(2,057)$. Similarly, on the basis of frequency alone, one would expect to find subjects missing more substitutions in which $\mathrm{e}$ is replaced by $f$ than when $f$ is replaced by e, since the frequency of e $(11,620)$ is much greater than that of $f(1,563)$. However, Experiment 2 did not reveal such an asymmetry for the letters $e$ and $f$.

\section{GENERAL DISCUSSION}

The three experiments reported here confirm the important role of visual factors in proofreading and support the hypothesis that proofreaders scan a visual representation of the text when searching for misspellings. When the correct letter and the one that replaced it in a misspelled word were visually similar, many more errors were made than when the two letters were dissimilar. The fact that visual similarity was responsible for this effect, rather than some linguistic factors, was supported by finding large effects of the type case in which the letters were printed.

The experiments also provide evidence for a particular set of information processing rules that are applied by the proofreaders to the visual representation of the text. A hierarchical feature test is implicated, in which subjects give greatest weight to resolving the shape and envelope of the letters and only secondarily discriminate additional features. If the envelope conforms to their expectations, the subjects adopt an asymmetrical decision rule in which they tolerate missing letter features but are intolerant of additional features. These information processing rules are suggested by the finding that subjects make more proofreading errors when the substituted letter is missing one of the features of the correct letter (as when e is replaced by c) than when the substituted letter has an additional feature (as when $c$ is replaced by e) but that this difference occurs only when the correct letter and the one replacing it have the same envelope.

Although the present results provide strong evidence for a hierarchy of levels of discrimination, the results do not provide information about the temporal order in which the levels are processed. One likely possibility, as suggested by the work of Lupker (1979), is that subjects first resolve letter shape and envelope and then process additional features. Peripheral vision may be sufficient for the resolution of letter envelope, whereas foveal vision may be necessary to resolve additional letter features. However, the present results are also consistent with the possibility that the two levels of discrimination are processed in parallel, so that all letter features are processed at the same time, but more weight is given to those features defining shape or envelope than to the remaining letter features.

One important question left unanswered by this research concerns the extent to which the information processing rules employed by proofreaders are determined by the quality of the printed text they are reading. In the present experiment, great care was exercised to insure that the copies of the typewritten text were clear. Hence, it was rarely, if ever, the case that visual features, such as the horizontal line segment in the letter $e$, were actually missing from the printed text. If the horizontal feature in the letter e had been frequently missing or dimmed, subjects would have made many proofreading errors when $\mathrm{c}$ was replaced by $\mathrm{e}$. However, subjects did not make very many errors on this type of substitution. Nevertheless, the subjects' previous vast experience with poor quality reproductions may have led them to adopt a strategy in which they expected, and hence tolerated, missing visual features. Perhaps under another set of perceptual conditions, in which subjects would expect irrelevant additional visual features rather than missing features, the subjects' information processing strategies would be different and an asymmetry would be found in a direction opposite to that found in the present study. The hypothesis that different patterns of errors would be found under different perceptual conditions is supported by the results of a study by Garner and Haun (1978). In an experiment involving tachistoscopic letter identification, they found that the distribution of errors depended on the type of perceptual limitation. Specifically, with a state limitation, which was produced by reducing stimulus duration, a letter with more features was mistaken for a letter with fewer features more often 
than the reverse. However, this asymmetric pattern of results was not obtained with a process limitation, which was produced by distorting the letter patterns by both adding and deleting line segments.

Whether or not future studies reveal that different perceptual conditions lead proofreaders to adopt different information processing strategies, the present results are interesting because they involve perceptual conditions that are commonly encountered by proofreaders in everyday situations.

\section{REFERENCES}

Aronson, E. The social animal. San Francisco: Freeman, 1972. Brondbent, D. E. Word-frequency effect and response bias. Psychological Review, 1967, 74, 1-15.

BoumA, H. Visual recognition of isolated lower-case letters. Vision Research, 1971, 11, 459-474.

Bouwhuis, D., \& Bouma, H. Visual word recognition of threeletter words as derived from the recognition of the constituent letters. Perception \& Psychophysics, 1979, 25, 12-22.

CoHEN, G. Reading and searching for spelling errors. In U. Frith (Ed.), Cognitive processes in spelling. London: Academic Press, 1980.

Corcoran, D. W. J. An acoustic factor in letter cancellation. Nature, 1966, 210, 658.

Corcoran, D. W. J. Acoustic factor in proof reading. Nature, $1967,214,851-852$.

Corcoran, D. W. J., \& Weening, D. L. Acoustic factors in visual search. Quarterly Journal of Experimental Psychology, 1968, 20, 83-85.

GARNer, W. R., \& HAUn, F. Letter identification as a function of type of perceptual limitation and type of attribute. Journal of Experimental Psychology: Human Perception and Performance, 1978, 4, 199-209.

Gilmore, G. C., Hersh, H., Caramazza, A., \& Griffin, J. Multidimensional letter similarity derived from recognition errors. Perception \& Psychophysics, 1979, 25, 425-431.

Haber, R. N., \& Schindler, R. M. Error in proofreading: Evidence of syntactic control of letter processing? Journal of Experimental Psychology: Human Perception and Performance, 1981,7, 573-579.

Healy, A. F. Proofreading errors on the word the: New evidence on reading units. Journal of Experimental Psychology: Human Perception and Performance, 1980, 6, 45-57.

Hols rook, M. B. Effect of subjective interletter similarity, perceived word similarity, and contextual variables on the recog- nition of letter substitutions in a proofreading task. Perceptual and Motor Skills, 1978, 47, 251-258.

Kučera, H., \& Francis, W. N. Computational analysis of present-day American English. Providence, R.I: Brown University Press, 1967.

Lindsay, P. H., \& Norman, D. A. Human information processing: An introduction to psychology (2nd ed.). New York: Academic Press, 1977.

LUPKER, S. J. On the nature of perceptual information during letter perception. Perception \& Psychophysics, 1979, 25, 303312.

MAcKAy, D. G. Phonetic factors in the perception and recall of spelling errors. Neuropsychologia, 1968, 6, 321-325.

Massaro, D. W., \& Schmulten, J. Visual features, preperceptual storage, and processing time in reading. In $\mathrm{D}$. W. Massaro (Ed.), Understanding language: An information processing analysis of speech perception, reading, and psycholinguistics. New York: Academic Press, 1975.

Mayzner, M. S., \& Tresselt, M. E. Tables of single-letter and digram frequency counts for various word-length and letterposition combinations. Psychonomic Monograph Supplements, $1965,1,13-32$.

Miller, G. A. Nonverbal communication. In G. A. Miller (Ed.), Communication, language, and meaning: Psychological perspectives. New York: Basic Books, 1973.

Podgorny, P., \& Garnen, W. R. Reaction time as a measure of inter- and intraobject visual similarity: Letters of the alphabet. Perception \& Psychophysics, 1979, 26, 37-52.

Rumelhart, D. E., \& Siple, P. Process of recognizing tachistoscopically presented words. Psychological Review, 1974, 81, 99-113.

Townsend, J. T. Theoretical analysis of an alphabetic confusion matrix. Perception \& Psychophysics, 1971, 9, 40-50.

Tvensxy, A. Features of similarity. Psychological Review, 1977, 84, 327-352.

\section{NOTE}

1. Although the names of the letters $\mathrm{c}$ and e may be closer phonetically than the names of the letters $s$ and $c$ or $e$ and $o$, the phonemes represented by the letters $c$ and $e$ are less similar than the phonemes represented by $s$ and $c$ or $e$ and o. Furthermore, the words formed by interchanging $c$ and $e$ should be less close phonetically than those formed by interchanging $s$ and $c$ or $e$ and $o$.

(Received for publication November 1, 1980; revision accepted March 24, 1981.) 